\title{
Rapid Screening of Cultural Parameters for Extracellular Halophilic Glutaminase Production from Tetragenococcus Muriaticus FF5302 using the Plackett-Burman's Experimental Design
}

\author{
Sawitree DUERAMAE ${ }^{1, *}$, Patthinan VARICHANAN ${ }^{1}$ and Toshiki ENOMOTO ${ }^{2}$ \\ ${ }^{1}$ Department of Applied Microbiology, Institute of Food Research and Product Development, \\ Kasetsart University, Bangkok 10900, Thailand \\ ${ }^{2}$ Department of Food Science, Ishikawa Prefectural University, Nonoichi, Ishikawa, Japan
}

('Corresponding author's e-mail: sawitree.der@ku.ac.th)

Received: 31 December 2019, Revised: 19 June 2020, Accepted: 30 July 2020

\begin{abstract}
The Plackett-Burman's experiemental design was used to efficiently select the key cultural parameters for the production of halophilic glutaminase by moderating halophilic bacterium Tetragenococcus muriaticus FF5302. Eleven variables were selected, which involved glutamine, peptone, yeast extract, glucose, fructose, $\mathrm{KCl}, \mathrm{MgSO}_{4}, \mathrm{NaCl}$, temperature, $\mathrm{pH}$, and inoculum size, to identify the most significant variables affecting halophilic glutaminase production in 12 experimental trials. The results of the statistical analyses demonstrated that glutamine, $\mathrm{pH}$, and temperature had significant effects on halophilic glutaminase production. The maximum halophilic glutaminase activity of $199.27 \mathrm{U} \mathrm{mL}^{-1}$ was observed after $120 \mathrm{~h}$ of fermentation. After Plackett-Burman's design experiments, the glutaminase activity was found to be 2.28 folds increase compared to basal conditions. Thus, the cultivation of $T$. muriaticus FF5302 under the optimal condition could enhance the production of halophilic glutaminase enzyme effectively.
\end{abstract}

Keywords: Cultural parameter, Halophilic glutaminase, Plackett-Burman design, Screening, Tetragenococcus muriaticus

\section{Introduction}

L-glutaminase (L-glutamine amidohydrolase, EC 3.5.1.2) is the important enzyme that catalyzes the deamination of L-glutamine to L-glutamic acid and ammonium ions [1]. Recently, L-glutaminase has received much attention concerning its therapeutic and industrial applications. It acts as a potent antileukemic agent and shows flavor-enhancing capacity in the production of fermented foods. Glutaminase is often used in Chinese traditional fermented foods such as soy sauce, and fermented beans, etc. Glutaminolytic enzymes are produced by many organisms like plants, animal tissues, and microorganisms, including bacteria, yeasts, and fungi. In general, glutaminases from Aeromonas veronii [2], Aspergillus flavus [3], A. niger [4], A. oryzae [5], Bacillus subtilis [6], Clostridium welchii [7], Escherichia coli [8], Pseudomonas stutzeri [9], Rhizobium etli [10], Streptomyces canarius [11], Vibrio costicola [12], and Zygosaccharomyces rouxii [13] have been isolated and well-studied.

To date, many reports have been published on the optimization of different microbiological parameters and fermentation strategies to produce glutaminase. However, since most industrial processes are typically performed under extreme operating conditions, it is of great importance to identify the types of enzymes which retain their optimal activities at various ranges of $\mathrm{pH}$ values, temperatures, and salt concentrations [14]. As researchers search for additional enzymes to improve existing biotechnological applications or design entirely new ones, halophilic organisms and the enzymes they produce are gaining 
attention. Interestingly, researchers are turning to archaea as the sources of halophilic enzymes [15]. Since halophilic enzymes adapt well to harsh conditions and are unusually tolerant, they could serve as suitable candidates for different industrial processes. Halophilic enzymes are active and stable in hypersaline environments or media with low water activity because, even in these conditions, enough water is present for them to retain a suitable charge distribution at the active site, maintaining the conformation of the enzyme $[16,17]$. Therefore, their usefulness for biotechnological applications stems from their ability to remain active in the presence of low water conditions. These adaptations would prove useful in harsh industrial process environments where enzymatic reactions may be carried out in an organic solvent [18].

However, it is difficult to identify the most important factors and to optimize them when several factors are involved in biotechnological processes. The traditional "One-Factor-At-a-Time" (OFAT) method used for optimizing a multivariable system is time-consuming and requires a large number of experiments, and it also fails to consider the interaction effects among variables [19-21]. The OFAT method for medium optimization involves changing 1 variable at a time by maintaining the others at fixed levels $[19,22]$. However, statistical experimental design techniques provide a more balanced alternative to the OFAT method for fermentation improvement. Specifically, the Plackett-Burman's experimental design is a 2-level fractional factorial design method; it useful for screening the main factors from a large set of parameters for its unbiased estimates of the linear effects of all factors with the maximum accuracy for a given number of observations [23]. This design is quite useful in preliminary studies, where the principal objective is to select variables that can be fixed or eliminated in further optimization processes based on the response surface methodology. Thus, it is important to determine the most suitable nutrients and cultural conditions required to achieve higher productivity [24]. In the present study, a preliminary analysis of the factors that affect halophilic glutaminase production was performed by moderately halophilic bacterium Tetragenococcus muriaticus FF5302, using the Plackett-Burman design to determine the most important variables among the culture conditions that affected halophilic glutaminase production.

\section{Materials and methods}

\section{Microorganism}

T. muriaticus FF5302, which is a good halophilic glutaminase producer, was isolated from Thai fermented fish sauce samples (Nam-pla), a fermented fish product. The culture was grown on Sehgal and Gibbons complex (SGC) agar comprising the following constituents $\left(\mathrm{g} \mathrm{L}^{-1}\right)$ : Casamino acid 7.5, yeast extract $10, \mathrm{KCl} 2$, trisodium citrate $3, \mathrm{MgSO}_{4} .7 \mathrm{H}_{2} \mathrm{O} 20, \mathrm{FeCl}_{2} .7 \mathrm{H}_{2} \mathrm{O} 0.01, \mathrm{NaCl} 200$, agar 15 in $1,000 \mathrm{~mL}$ distilled water pH 6.8 - 7.0 [25] and supplemented with $20 \%(\mathrm{w} / \mathrm{v}) \mathrm{NaCl}$. Then, it was incubated at $37^{\circ} \mathrm{C}$ for 5 - 7 days. The culture was maintained on SGC slants at $-20^{\circ} \mathrm{C}$

\section{Halophilic glutaminase production in shaken flasks}

Inoculum was prepared by transferring 1 loop of the selected strain into $9 \mathrm{~mL}$ of SGC seed medium ( $\mathrm{pH} 6.8$ - 7.0), which contained the optimal $\mathrm{NaCl}$ concentration, and the culture was incubated on a rotary shaker $(200 \mathrm{rpm})$ at $37{ }^{\circ} \mathrm{C}$ for 5 - 7 days. Twelve experimental runs were performed in $250 \mathrm{~mL}$ Erlenmeyer flasks, where the medium components were added to the flasks at various concentrations based on the Plackett-Burman's design. All the experimental runs were performed in triplicate and the average observation was used as the response (halophilic glutaminase activity) in the design. Inoculation was performed using various concentrations of $1-3 \%(\mathrm{v} / \mathrm{v})$ seed culture, which had been grown for 3 days in the medium described above. The inoculated media were incubated on a rotary shaker $(200 \mathrm{rpm})$ at various initial $\mathrm{pH}(6-8)$ and temperature $\left(37-42^{\circ} \mathrm{C}\right)$ levels for $120 \mathrm{~h}$. Next, $5 \mathrm{~mL}$ culture samples were removed aseptically after $120 \mathrm{~h}$ and centrifuged at $8,000 \times g$ and $4{ }^{\circ} \mathrm{C}$ for $20 \mathrm{~min}$. The cell-free supernatants were used as crude enzyme solutions in the halophilic glutaminase activity assays. 


\section{Glutaminase activity assays}

The glutaminase activity was measured by using a modified version of Nessler's reagent method described by [26]. The activity of the enzyme was determined calorimetrically from the proportional release of ammonium ions after adding Nessler's reagent to the sample. An aliquot of $0.5 \mathrm{~mL}$ of the sample enzyme preparation was mixed with $0.5 \mathrm{~mL}$ of $0.2 \mathrm{M}$ glutamine solution. After $30 \mathrm{~min}$ of incubation at room temperature, the mixture reaction was arrested by the addition of $1.0 \mathrm{~mL}$ of $10 \%$ trichloroacetic acid (TCA). Enzyme mixture preparation, Nessler's reagent and distilled water were added in a proportion of $0.1,0.2$, and $3.7 \mathrm{~mL}$ respectively. The enzyme activity was calculated from the absorbance spectra by using a spectrophotometer at $450 \mathrm{~nm}$. One unit of glutaminase was calculated as the amount of enzyme liberating $1 \mu \mathrm{M}$ of ammonia under optimum conditions [1].

\section{Plackett-Burman design}

The purpose of this optimization step was to identify the culture condition parameters with significant effects on halophilic glutaminase production. The Plackett-Burman's design is very useful for screening the most important factors [27]. This design does not consider the interaction effects between variables, and it is used to screen the most important variables that affect halophilic glutaminase production [28]. The total number of experiments is $n+1$, where $n$ is the number of variables, which can be represented by a $1^{\text {st }}$-order polynomial equation (1):

$\mathrm{Y}=\beta 0+\sum \beta \mathrm{i} \mathrm{xi}$

where $\mathrm{Y}$ represents the response (enzyme activity), $\beta 0$ is the model coefficient, $\beta \mathrm{i}$ is the linear coefficient, and $x i$ is the level of the independent variable.

This model does not describe the interactions among factors, and it is used to screen and evaluate the important factors that influence the response. Thus, 11 variables were selected, i.e., glutamine, peptone, yeast extract, glucose, fructose, $\mathrm{KCl}, \mathrm{MgSO}_{4}, \mathrm{NaCl}$, temperature, $\mathrm{pH}$, and inoculum size, which were screened in 12 experimental runs using the Plackett-Burman design. Table 1 lists the selected variables and the ranges used in the study. The concentration levels were determined based on previous reports of glutaminase production using different substrates. Each independent variable was investigated at high $(+)$ and low $(-)$ levels, as shown in Table 1. The insignificant variables were eliminated to obtain a smaller, more manageable set of factors. All the trials were performed in triplicate and the average observation was used as the response (halophilic glutaminase activity) in the design. The experimental ranges and the levels of the nutritional components used in the Plackett-Burman screening design are represented in Table 2 in terms of their actual and coded values. Twelve experimental runs were performed in $250 \mathrm{~mL}$ Erlenmeyer flasks according to the design matrix. All the flasks were inoculated with the inoculum at $1-3 \%(\mathrm{v} / \mathrm{v})$, as indicated by the design. The flasks were incubated at $37-42{ }^{\circ} \mathrm{C}$ and the halophilic glutaminase activity was determined for $120 \mathrm{~h}$. The statistical software package DesignExpert (version 6.0.2, Stat-Ease Corporation, USA) was used to analyze the experimental data.

Table 1 Ranges of different factors studied using the Plackett-Burman's design.

\begin{tabular}{|c|c|c|c|c|c|c|c|c|c|c|c|}
\hline \multirow{2}{*}{ Level } & \multicolumn{11}{|c|}{ Factors } \\
\hline & $\mathbf{A}$ & B & $\mathrm{C}$ & D & $\mathbf{E}$ & $\mathbf{F}$ & $\mathbf{G}$ & H & I & $\mathbf{J}$ & $K$ \\
\hline- & 1 & 1 & 5 & 1 & 1 & 1 & 10 & 10 & 6 & 37 & 1 \\
\hline+ & 3 & 3 & 10 & 3 & 3 & 3 & 20 & 20 & 8 & 42 & 3 \\
\hline
\end{tabular}

A: Glutamine $(\%, w / v)$; B: Peptone $(\%, w / v)$; : Yeast extract $\left(\mathrm{g} \mathrm{L}^{-1}\right)$; D: Glucose $\left(\mathrm{g} \mathrm{L}^{-1}\right)$; E: Fructose $(\mathrm{g}$ $\left.\mathrm{L}^{-1}\right) ; \mathrm{F}: \mathrm{KCl}\left(\mathrm{g} \mathrm{L}^{-1}\right) ; \mathrm{G}: \mathrm{MgSO}_{4}\left(\mathrm{~g} \mathrm{~L}^{-1}\right) ; \mathrm{H}: \mathrm{NaCl}(\%, \mathrm{w} / \mathrm{v}) ; \mathrm{I}: \mathrm{pH}$; J: Temperature $\left({ }^{\circ} \mathrm{C}\right)$; K: Inoculum size $(\%, \mathrm{v} / \mathrm{v})$ 


\section{Results and discussion}

\section{Identification of important variables by Plackett-Burman's Experimental Design}

The Plackett-Burman's design was conducted to identify factors with positive effects on halophilic glutaminase production. The effects of 11 parameters on halophilic glutaminase production by T. muriaticus FF5302 were analyzed. Table 2 shows the Plackett-Burman design of the experiments and the results obtained from the experiments, which were generated using Design-Expert. Table 2 also shows that the variation in halophilic glutaminase activity was $95.34-199.27 \mathrm{U} \mathrm{mL}^{-1}$. The highest and lowest glutaminase production levels were 199.27 and $95.34 \mathrm{U} \mathrm{mL}^{-1}$ in runs 11 and 7, respectively. This indicates that various factors had major effects on glutaminase production. The 2 values of each variable [maximum $(+)$ and minimum $(-)$ ] were selected such that the difference between the 2 values $(+$ and -$)$ was sufficiently large to include the peak area with the maximum enzyme production level. Statistical analyses of the responses were performed, and the results are shown in Table 3. The model F-value of 29.46 implies that the model is significant because there was only a $0.01 \%$ chance that a model F-value this large could be attributable to noise. The model terms were significant $(p \leq 0.05)$. The magnitudes of the effects indicate the level of significance for each factor during glutaminase production. Among the screened factors, glutamine (A), $\mathrm{pH}(\mathrm{I})$, and temperature $(\mathrm{J})$ were identified as the most significant variables that affected glutaminase production (Table 3). The statistical analysis showed that glutaminase production was affected by these 3 variables based on the F-values and $p$-values shown in Table 3. In addition, the coefficient of determination $\left(\mathrm{R}^{2}\right)$ for the model was 0.9870 ; thus, the modeled factors explained $98.70 \%$ of the variability in the data. The coefficient of variation (CV) is the ratio of the standard error of the estimate relative to the mean value of the observed response (as a percentage). Thus, $\mathrm{CV}$ is a measure of the reproducibility of the model, and a model is generally considered to be reasonably reproducible if $\mathrm{CV} \leq 10 \%$ [29]. The low $\mathrm{CV}$ value $(8.93 \%)$ obtained demonstrates that the experimental values had a high degree of precision and reliability.

Table 2 The Plackett-Burman design used to evaluate 11 variables with coded values for glutaminase production by T. muriaticus FF5302 and the response of the design.

\begin{tabular}{|c|c|c|c|c|c|c|c|c|c|c|c|c|c|}
\hline \multirow{2}{*}{ Run } & \multicolumn{11}{|c|}{ Variables } & \multicolumn{2}{|c|}{ Glutaminase activity $\left(\mathrm{U} \mathrm{mL}^{-1}\right)$} \\
\hline & $\mathbf{A}$ & $\mathbf{B}$ & $\mathbf{C}$ & $\mathbf{D}$ & $\mathbf{E}$ & $\mathbf{F}$ & $\mathbf{G}$ & $\mathbf{H}$ & $\mathbf{I}$ & $\mathbf{J}$ & $\mathbf{K}$ & Experimental & Predicted \\
\hline 1 & - & + & - & - & - & + & + & + & - & + & + & 123.22 & 114.72 \\
\hline 2 & - & + & + & - & + & - & - & - & + & + & + & 152.04 & 149.11 \\
\hline 3 & + & + & - & + & - & - & - & + & + & + & + & 184.42 & 194.53 \\
\hline 4 & - & - & - & + & + & + & - & + & + & - & - & 107.32 & 114.60 \\
\hline 5 & + & - & + & - & - & - & + & + & + & - & - & 178.69 & 160.03 \\
\hline 6 & + & - & + & + & - & + & - & - & - & + & + & 164.38 & 160.14 \\
\hline 7 & - & - & - & - & - & - & - & - & - & - & - & 95.34 & 80.23 \\
\hline 8 & - & + & + & + & - & + & + & - & + & - & - & 105.66 & 114.61 \\
\hline 9 & - & - & + & + & + & - & + & + & - & + & + & 104.42 & 114.72 \\
\hline 10 & + & + & - & + & + & - & + & - & - & - & - & 114.55 & 125.64 \\
\hline 11 & + & - & - & - & + & + & + & - & + & + & + & 199.27 & 194.53 \\
\hline 12 & + & + & + & - & + & + & - & + & - & - & - & 119.19 & 125.64 \\
\hline
\end{tabular}

A: Glutamine $(\%, w / v) ;$ B: Peptone $(\%, w / v) ; C$ : Yeast extract $\left(\mathrm{g} \mathrm{L}^{-1}\right)$; D: Glucose $\left(\mathrm{g} \mathrm{L}^{-1}\right)$; E: Fructose (g $\left.\mathrm{L}^{-1}\right)$; F: $\mathrm{KCl}\left(\mathrm{g} \mathrm{L}^{-1}\right) ; \mathrm{G}: \mathrm{MgSO}_{4}\left(\mathrm{~g} \mathrm{~L}^{-1}\right) ; \mathrm{H}: \mathrm{NaCl}\left(\%\right.$ w/v); I: $\mathrm{pH} ; \mathrm{J}$ : Temperature $\left({ }^{\circ} \mathrm{C}\right)$; $\mathrm{K}$ : Inoculum size $(\%, \mathrm{v} / \mathrm{v})$ 
Regression analysis was performed on the results and a $1^{\text {st }}$-order polynomial Eq. (2) was derived that represented glutaminase production as a function of the independent variables.

$\mathrm{Y}=300.93-22.71 \mathrm{~A}-17.19 \mathrm{I}-6.90 \mathrm{~J}$

The most important factor associated with the expression of glutaminase activity is usually the nitrogen source because glutaminases are inducible enzymes. Thus, glutamine was found to be the most suitable nitrogen source for inducing glutaminase production, which agreed with the results reported by [30]. L-glutamine plays a vital role in cellular nitrogen metabolism since it serves as an important nitrogen carrier. Microorganisms derive most of their nitrogen from the conversion of glutamate to $\alpha$ ketoglutarate by the action of glutamate dehydrogenase. Glutamine would be generated by glutamine synthase with glutamate and nitrogen, but at the expense of energy [31,32]. When abundant glutamine is available in the culture medium, however, L-glutaminase, the putative enzyme, is produced in copious amounts to convert L-glutamine to L-glutamate. Thus glutamine, the medium nutrient factor, is an excellent way of inducing L-glutaminase. Kiruthika et al. [33] also reported that glutamine had a significant effect on glutaminase production. The result is in good correlation with the literature reports where El-Syed [34] reported maximal glutaminase production at $2 \%$ L-glutamine in the medium. It depicts that indeed the amide nitrogen of glutamine was a source of amino groups in a wide range of biosynthetic processes and it is also frequently involved in protein active or binding sites. Besides, nitrogen sources are secondary energy sources for organisms, and they play an important role in the growth and production of valuable enzymes of organisms. The nature of the compound and the concentration might influence or downregulate enzyme production [35]. Glutaminase activity was increased and was associated with both increased culture medium $\mathrm{pH}$ and improved cell survival [36]. The effect of temperature on glutaminase production has been reported that at high temperatures, microorganisms may synthesize only a reduced number of proteins essential for growth and other physiological processes [37]. Similar observations were reported for glutaminase from Trichoderma koningii which produced $15.59 \mathrm{U} \mathrm{gds}^{-1}$ at $33{ }^{\circ} \mathrm{C}$ [34]. Kumar et al. [38] found that temperature had a significant effect on the production of the enzyme.

Table 3 Statistical analysis of the model.

\begin{tabular}{lccccc}
\hline \multicolumn{1}{c}{ Source } & Sum of squares & Degrees of freedom & Mean square & F-value & $\boldsymbol{p}>\mathbf{F}$ \\
\hline Model & 13305.41 & 3 & 4435.14 & 29.46 & 0.0001 \\
A & 6188.02 & 1 & 6188.02 & 41.11 & 0.0002 \\
I & 3546.64 & 1 & 3546.64 & 23.56 & 0.0013 \\
J & 3570.75 & 1 & 3570.75 & 23.72 & 0.0012 \\
Residual & 1204.23 & 8 & 150.53 & & \\
Corr. Total & 14509.64 & 11 & & & \\
\hline
\end{tabular}

$\mathrm{R}^{2}=0.9870 ;$ Adj. $\mathrm{R}^{2}=0.9559 ; \mathrm{CV}=8.93 \%$

\section{Conclusions}

The findings of this study have been demonstrated the benefit of using the Plackett-Burman design as a preliminary optimization technique because it supported the screening and evaluation of factors that affect halophilic glutaminase production by moderately halophilic bacterium T. muriaticus FF5302. Among the factors tested glutamine, $\mathrm{pH}$, and temperature had the most significant effects on halophilic glutaminase production. After $120 \mathrm{~h}$ of fermentation, the predicted model fitted well with the experimental results $\left(199.27 \mathrm{U} \mathrm{mL}^{-1}\right)$. After Plackett-Burman's design experiments, the glutaminase activity was found to be 2.28 folds increase compared with the basal condition $\left(87.39 \mathrm{U} \mathrm{mL}^{-1}\right)$. This 
demonstrates that testing all factors simultaneously may be a powerful and useful statistical approach for the rapid identification of production parameters. Subsequently, further statistical optimization needs to be conducted using the response surface methodology based on the medium and process parameters.

\section{Acknowledgement}

The authors thank the Kasetsart University Research Fund 2018 for providing the financial support. We also thank the Department of Applied Microbiology, Institute of Food Research and Product Development, Kasetsart University, Thailand for the technical assistance. Finally, we are very thankful to Rayong Fish Sauce Industry Co., Ltd (Rayong) for the fish sauce samples.

\section{References}

[1] A Sabu, TR Keerthi, SR Kumar and M Chandrasekaran. L-glutaminase production by marine Beauveria sp. under solid state fermentation. Process Biochem. 2000; 35, 705-10.

[2] SAV Jesuraj, MMR Sarker, LC Ming, SMJ Praya, M Ravikumar and MT Wui. Enhancement of the production of L-glutaminase, an anticancer enzyme, from Aeromonas veronii by adaptive and induced mutation techniques. PLoS One 2017; 12, 1-17.

[3] MA Abu-Tahon and GS Isaac. Purification, characterization and anticancer efficiency of Lglutaminase from Aspergillus flavus. J. Gen. Appl. Microbiol. 2019; 65, 284-92.

[4] JE Nagamani. Production, partial purification and assay of L-glutaminase enzyme from Aspergillus niger by solid state fermentation. Int. J. Res. Rev. 2018; 5, 177-81.

[5] C Thammarongtham, G Turner, AJ Moir, M Tanticharoen and S Cheevadhanarak. A new class of glutaminase from Aspergillus oryzae. J. Mol. Microbiol. Biotechnol. 2001; 3, 611-7.

[6] Y Shimizu, A Ueyama and K Goto. Purification and characterization of glutaminase from Bacillus subtilis GT strain. J. Brew. Soc. Jpn. 1991; 86, 441-6.

[7] DE Hughes and DH Williamson. Some properties of the glutaminase of Clostridium welchii. Biochem. J. 1952; 51, 45-55.

[8] AF Yakunin. Functional and structural characterization of four glutaminases from Escherichia coli and Bacillus subtilis. Biochemistry 2008; 47, 5724-35.

[9] R Athira, T Elizebeth, T Narendra, T Sheik, S Gupta, M Chaudary, K Siddalingeshwara and T Pramod. Investigation on the production of L-glutaminase from Pseudomonas stutzeri strain under solid state fermentation using various agro residues. J. Drug Deliv. Ther. 2014; 4, 81-5.

[10] J Calderón, A Huerta-Saquero, GD Pont and S Durán. Sequence and molecular analysis of the Rhizobium etli glsa gene, encoding a thermolabile glutaminase. Biochim. Biophys. Acta Gene. Struct. Expr. 1999; 1444, 451-6.

[11] FM Reda. Kinetic properties of Streptomyces canarius L- Glutaminase and its anticancer efficiency. Braz. J. Microbiol. 2014; 46, 957-68.

[12] GN Prabhu and M Chandrasekaran. Purification and characterization of an anti-cancer enzyme produced by marine Vibrio Costicola under a novel solid state fermentation process. Braz. Arch. Biol. Tech. 1999; 42, 363-7.

[13] PV Iyer and RS Singhal. Glutaminase production using Zygosaccharomyces rouxii NRRL-Y 2547: effect of aeration, agitation regimes and feeding strategies. Chem. Eng. Tech. 2010; 33, 52-62.

[14] X Li and $\mathrm{HY} \mathrm{Yu}$. Characterization of a novel extracellular lipase from a halophilic isolate, Chromohalobacter sp. LY7-8. Afr. J. Microbiol. Res. 2012; 6, 3516-22.

[15] SD Schreck and AM Grunden. Biotechnological applications of halophilic lipases and thioesterases. Appl. Microbiol. Biotechnol. 2014. 98, 1011-21.

[16] SD Sarma and PD Sarma. Halophiles and their enzymes: Negativity put to good use. Curr. Opin. Microbiol. 2015; 25, 120-6.

[17] J Eichler. Biotechnological uses of archaeal extremozymes. Biotechnol. Adv. 2001; 19, 261-78. 
[18] B Sana, D Ghosh, M Saha and J Mukherjee. Purification and characterization of an extremely dimethylsulfoxide tolerant esterase from a salt-tolerant Bacillus species isolated from the marine environment of the Sundarbans. Process Biochem. 2007; 42, 1571-8.

[19] X Huang, J Ge, J Fan, X Chen, X Xu, J Li, Y Zhang and D Zhou. Characterization and optimization of xylanase and endoglucanase production by Trichoderma viride HG 623 using response surface methodology (RSM). Afr. J. Microbiol. Res. 2013; 7, 4521-32.

[20] P Kumar and T Satyanarayana. Optimization of culture variables for improving glucoamylase production by alginate-entrapped Thermomucor indicae-seudaticae using statistical methods. Bioresource Tech. 2007; 98, 1252-9.

[21] Y Xiong, J Liu, H Song and L Ji. Enhanced production of extracellular ribonuclease from Aspergillus niger by optimization of culture conditions using response surface methodology. Biochem. Eng. J. 2004; 21, 27-32.

[22] A Rajendran, M Thirungnanam and V Thangavelu. Statistiscal evaluation of medium components by Plackett-Burman experimental design and kinetic modeling of lipase production by Pseudomonas fluorescens. Indian J. Biotechnol. 2007; 6, 469-78.

[23] R Saxena and R Singh. Statistical optimization of conditions for protease production from Bacillus sp. Acta Biol. Szeged. 2010; 54, 135-41.

[24] MN Reddy, CG Kumar, K Swathi, B Nagamani, S Venkateshwar and LV Rao. Extracellular alkaline protease production from isolated Bacillus Subtilis SVR-07 by using submerged fermentation. Int. J. Pharmaceu. Res. Biosci. 2011; 3, 126-223.

[25] SN Sehgal and NE Gibbons. Effect of some metal ions on the growth of Halobacterium cutirubrum. Can. J. Microbiol. 1960; 6, 165-9.

[26] A Imada, S Igarasi, K Nakahama and M Isono. Asparaginase and glutaminase activities of microorganisms. Microbiology 1973; 76, 85-99.

[27] BI Sarat, KK Sita and RG Hanumantha. Optimization of media constituents for the production of lipase in solid state fermentation by Yarrowia lipolytica from palm Kernal cake (Elaeis guineensis). Adv. Biosci. Biotechnol. 2010; 1, 115-21.

[28] RL Plackett and JP Burman. The design of optimum multi factorial experiments. Biom. J. 1946; 33, 305-25.

[29] G Li, P Wen, S Du and J Zeng. Response surface methodology for the optimization of preparation of sweet potato starch phosphates of high light transmittance. Advs. Biomed. Eng. 2011; 1-2, 194-7.

[30] T Sathith, KB Uppuluri, P Veera Bramha Chari and D Kezia. Sequential optimization methods for augmentation of marine enzymes production in solid-state fermentation: l-glutaminase production a case study. Adv. Food. Nutr. Res. 2016; 78, 95-114.

[31] B Magasanik. Ammonia assimilation by Saccharomyces cerevisiae. Eukaryot. Cell 2003; 2; 827-9.

[32] N Rehm, T Georgi, E Hiery, U Degner, A Schmiedl, A Burkovski A and M Bott. L-glutamine as a nitrogen source for Corynebacterium glutamicum: Derepression of the AmtR regulon and implications for nitrogen sensing. Microbiology 2010; 156, 3180-93.

[33] J Kiruthika, N Saraswathy and S Murugesan. Maximizing L-glutaminase production from marine Bacillus subtilis JK-79 under solid state fermentation. Afr. J. Biotechnol. 2018; 17, 288-305.

[34] AS El-Syed. L-glutaminase production by Trichoderma koningii under solid-state fermentation. Indian J. Microbiol. 2009; 49, 243-50.

[35] E Raju and G Divakar. Production of amylase by using Pseudomonas aeruginosa isolated from garden soil. Int. J. Adv. Pharm. Biol. Chem. 2013; 2, 50-6.

[36] JF Hunt, E Erwin, L Palmer, Vaughan J, Molhotra N, TAE Plattsmills and B Gaston. Expression and activity of $\mathrm{pH}$-regulatory glutaminase in the human airway epithelium. Am. J. Respir. Crit. Care Med. 2002; 165, 101-7.

[37] PV Gawande and MY Kamat. Production of Aspergillus xylanase by lignocellulosic waste fermentation and its application. J. Appl. Microbiol. 1999; 87, 511-9.

[38] R Kumar, S Mahajan, A Kumar and D Singh. Identification of variables and value optimization for optimum lipase production by Bacillus pumilus RK31 using statistical methodology. New Biotechnol. 2011; 28, 65-71. 